\title{
Studies into exfoliation and coating of Egyptian blue in methanol for application to the detection of latent fingermarks
}

\author{
Sorour Shahbazi ${ }^{*}$, John V. Goodpaster ${ }^{\mathrm{b}}$, Gregory D. Smith ${ }^{\mathrm{c}}$, Thomas Beckera,
} Simon W. Lewis ${ }^{a}$

${ }^{a}$ School of Molecular and Life Sciences, Curtin University, GPO Box U1987, Perth, Western Australia 6845, Australia

${ }^{b}$ Department of Chemistry and Chemical Biology, Forensic and Investigative Sciences Program, Indiana University Purdue University Indianapolis (IUPUI), 402 North Blackford Street, LD 326, Indianapolis, IN, 46202, USA

'Indianapolis Museum of Art at Newfields, 4000 Michigan Road, Indianapolis, IN, 46208, USA

* E-mail: Sorour.shahbazi@curtin.edu.au

\begin{abstract}
We have recently demonstrated that coated exfoliated Egyptian blue powder is effective for detecting latent fingermarks on a range of highly-patterned nonporous and semi-porous surfaces. In this extension of that work, we present our studies into an alternative approach to prepare exfoliated Egyptian blue coated with cetrimonium bromide and Tween ${ }^{\circledR} 20$ using a simpler technique. The quality of the latent fingermarks developed with these exfoliated powders and the commercial powder were compared in a comprehensive study. Depletion series of natural fingermarks from a wide range of donors (12 males and females) deposited on non-porous (glass slides) and semi-porous (Australian banknotes) surfaces were used in this study. Enhancement in the performance of the coated exfoliated particles compared to the commercial powder was observed, particularly in the case of aged fingermarks and polymer banknotes as challenging substrates.
\end{abstract}

Keywords: Forensic science, latent fingermarks, NIR luminescence, Egyptian blue, liquid-exfoliation 


\section{Introduction}

Latent fingermarks discovered in criminal cases have long played an important role in identifying individuals owing to their characteristic patterns. However, this first relies on the successful visualisation of a latent fingermark. Although there is a wide range of chemical and physical detection methods available, a considerable number of latent fingermarks remain undetected [1-3]. This could be a result of a lack of sensitivity or selectivity of the applied methods to small amounts of fingermark residue [4-6]. In addition, detection of latent fingermarks deposited on dark, multi-coloured, or multi-patterned substrates remains a significant challenge since the contrast between the ridge details and the underlying substrate is decreased here [7].

Luminescence-based development techniques and light-filtering technology can enable background interference to be suppressed or eliminated, particularly by utilising the near-infrared (NIR) region (700-1000 nm) of the spectrum in which only a limited number of substrates luminesce [요, $\underline{9}]$.

Ancient Egyptian blue $\left(\mathrm{EB}, \mathrm{CaCuSi}_{4} \mathrm{O}_{10}\right)$ pigment strongly luminesces at $910 \mathrm{~nm}$ when excited with visible light $\left(\lambda_{\max }=630 \mathrm{~nm}\right)$ [10-13]. The NIR-luminescence, relatively low-cost, and non-toxicity of $\mathrm{EB}$ render it as a desirable fingermark dusting powder [14]. However, the relatively large size of the commercial EB particles (i.e., tens of microns) may result in overdevelopment and lack of clear ridge details [14]. Therefore, the size of the particles should be decreased from commercial artists material.

The high durability of EB particles makes reducing their size challenging. In a recent study, following a technique introduced by Johnson-McDaniel et al. [15], exfoliation of EB in hot water (approximately $80^{\circ} \mathrm{C}$ ) resulted in finer particles containing nanoplates and nanosheets [16]. The exfoliated particles were successfully applied for the detection of latent fingermarks [16]. The flat morphology of the exfoliated particles, similar to metal flake powders, may also enhance their adherence to the fingermark secretion due to an increased contact area [17-19]. 
There are three important parameters that affect the exfoliation process of layered structures using the liquid-phase exfoliation method: polarity of solvent, temperature, and ionic surfactant [20, 21]. In the liquid-phase exfoliation method, forces between the liquid and silicate layers should overcome intermolecular forces between adjacent silicate sheets. Also, stabilising the sheets with suitable surfactants prevents reaggregation.

To simplify the exfoliation process, one approach is to eliminate heating of a water slurry of pigment by instead using a polar organic solvent in combination with a surfactant that are effective at room temperature. Based on previous experiments and other reports, cetrimonium bromide (CTAB) is a suitable ionic surfactant for exfoliation and coating of EB particles [21]. It is also desirable in terms of fingermark development because of its ability to interact favourably through its hydrocarbon tail with fingermark secretions, adding a further ability to adhere EB particles to the fingermark [16]. Tween ${ }^{\circledR} 20$ as a non-ionic surfactant was used in previous reports to coat nanoparticles applied for the development of latent fingermarks [3, 22-24]. It contains a long hydrocarbon chain as well as hydroxyl and carboxyl functional groups, which can target components within the secretion. Methanol is a highly polar solvent, and due to the hydrocarbon chain in its structure, CTAB and Tween ${ }^{\circledR} 20$ can be dissolved easily at room temperature (Supplementary Data, Fig. A1). Therefore, methanol without and with either CTAB or Tween ${ }^{\circledR} 20$ was used instead of water to exfoliate EB particles at room temperature. Three types of dusting powders including uncoated, CTAB-coated, and Tween ${ }^{8} 20$-coated exfoliated particles were prepared, and their capability for the detection of latent fingermarks on different substrates was studied.

\section{Material and methods}

\subsection{Exfoliation and coating of Egyptian blue powder}

For the preparation of the pure exfoliated EB (EEB), $4 \mathrm{~g}$ of EB powder (Kremer Pigmente Inc., Germany, Catalogue No 10060) was vigorously stirred in $500 \mathrm{~mL}$ of methanol (Honeywell Burdick ${ }^{\circledR}$ \& Jackson, Catalogue No 230-4) in a capped 
Schott bottle using a glass-coated magnet stir bar at room temperature (20-26 $\left.{ }^{\circ} \mathrm{C}\right)$ for 12 days. The mixture was left overnight at room temperature to let the powder settle. The clear supernatant was decanted. Alternatively, the EEB particles could be isolated using a centrifuge (5000 rpm for $3 \mathrm{~min}$ ). The powder was left to dry overnight under ambient conditions or in an oven (ZRD-A5055, Zhicheng ${ }^{\circledR}$, China) at $30-35^{\circ} \mathrm{C}$. The dried powder lumps were crushed and sieved. To coat the EEB particles, the same procedure was followed with the addition of $1 \mathrm{~g}$ of CTAB ( $\geq 99 \%$, Sigma Life Science, Product No H9151) or $4 \mathrm{~mL}$ of Tween ${ }^{\circledR} 20$ (Sigma Life Science, Product No P1379) to the mixture of EB and methanol before stirring. EB, EEB, CTAB-coated EEB (EEB+C) and Tween ${ }^{\circledR} 20$ coated EEB (EEB+T20) powders were stored in an oven at $30-35{ }^{\circ} \mathrm{C}$ to minimise the possible agglomeration due to humidity.

\section{Results and discussion}

\subsection{Powder preparation}

Fig. 1 ( $\left.\mathbf{a}_{1}-\mathbf{d}_{1}\right)$ photos taken under visible light show that delamination into smaller particles changed the colour of the powder from dark blue to light purple-blue. This phenomenon was previously observed in the case of exfoliation in water [16]. According to previous studies, the size of EB particles affects the pigment's shade of blue $[15,25]$. Larger clusters of rectangular blue crystals consist of $\mathrm{Cu}^{2+}$ cations linked by silicate tetrahedra produce a darker blue colour of EB pigment and smaller clusters produce a lighter blue colour.

As demonstrated the luminescence images of the same powders in Fig. 1 ( (a2- $\left.\mathbf{d}_{2}\right)$, although the luminescence of the EB powder was decreased after long-term exfoliation compared to EB powder, the final products were still strongly luminescent (see Supplementary Data, Section A2 for photography details). To find the optimum illumination wavelength, powders were illuminated at different wavelengths from $350 \mathrm{~nm}$ to $650 \mathrm{~nm}$. Maximum brightness was achieved at $590 \mathrm{~nm}$ (Supplementary Data, Fig. A2). Therefore, illumination at $590 \mathrm{~nm}$ was applied for the investigations presented here. 


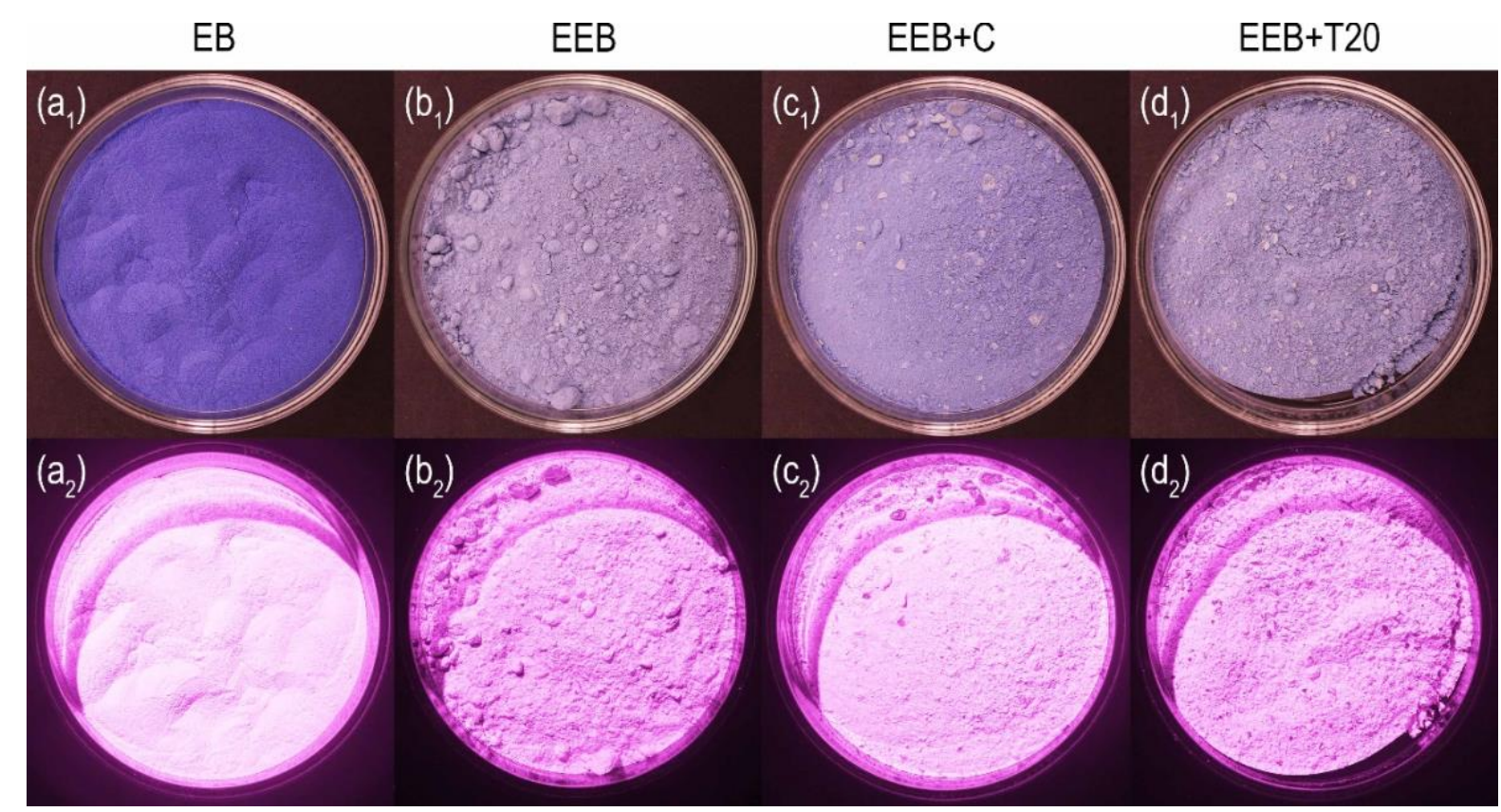

Fig. 1. Photographs of (a) EB, (b) EEB, (c) EEB+C and (d) EEB+T20 powders photographed by Canon camera under ( $\left(a_{1}-d_{1}\right)$ ambient lighting (f-stop: $f / 6.3$, exposure time: $\left.1 / 5 \mathrm{~s}\right)$ and under $\left(\mathrm{a}_{2}-\mathrm{d}_{2}\right)$ illumination at $590 \mathrm{~nm}$ with an IR long-pass filter (f-stop: f/6.3, exposure time: 1/10 s).

Brightness of the image was increased by $100 \%$.

Particles size affects the intensity of the attenuated total reflectance (ATR) Fourier transform infrared (FTIR) spectral peaks (see Supplementary Data, Section A3 for experimental and instrumental details). Absorption peaks are sharper and more intense when particles are finer [26-29]. Therefore, one technique to compare the particles size can be through their ATR spectrum (Supplementary Data, Section A3 for more explanation). Mid-infrared (MIR) spectra of EB before and after exfoliation in methanol without and with CTAB or Tween ${ }^{\circledR} 20$ were collected using a Nicolet FTIR (Fig. 2). The peak intensity increased after exfoliation in all spectra indicating a decrease in the size of the particles. This result is consistent with the lighter colour of the exfoliated particles (Fig. 1 ( $\left.\mathbf{a}_{1}-\mathbf{d}_{1}\right)$ ). Moreover, differences in the MIR spectra of the uncoated and coated particles could indicate the interaction of the surfactant with the surface of the particles. Fig. A3 (Supplementary Data) shows that symmetric and asymmetric stretching peaks of $\mathrm{C}-\mathrm{H}$ from the adsorbed CTAB appeared in the $\mathrm{EEB}+\mathrm{C}$ spectrum and slightly shifted compared to the peaks in the CTAB spectrum. However, as per Fig. A4 (Supplementary Data), no distinct changes were observed between the spectra of the uncoated and Tween ${ }^{\circledR}$ 
20-coated particles. This could be due to the intensive EEB spectrum that covered the possible minor differences (see Supplementary Data, Section A3 for more spectroscopy details).

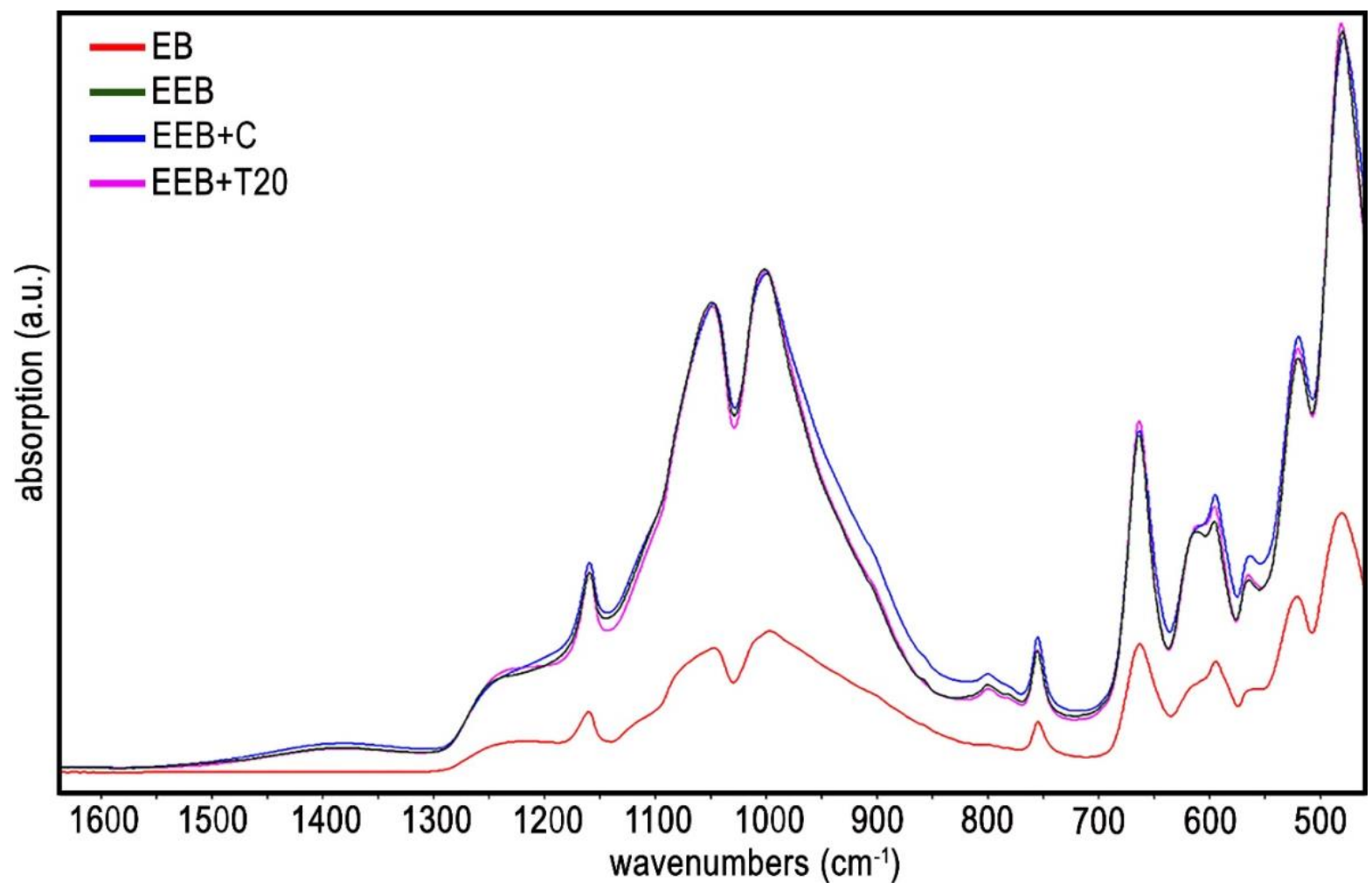

Fig. 2 MIR spectra of EB, EEB, EEB+C and EEB+T20 powders. No intensity modification was applied.

\subsection{Fingermark development}

Three sets of experiments were conducted to study the performance of the prepared powders for the detection of latent fingermarks, as per the following stages (Table 1):

- Stage 1: the sensitivity of the coarse particles (EB) was compared to the finer exfoliated ones (EEB, EEB+C and EEB+T20); a total of 288 impressions.

- Stage 2: the sensitivity of the commercial powder (EB) was compared to the most enhanced exfoliated powder (based on the results from Stage 1) on a challenging substrate; a total of 24 impressions.

Table 1 Demonstration of the experimental details applied in stages 1 and 2 


\begin{tabular}{|c|c|c|c|c|c|}
\hline & powder & substrate & $\begin{array}{c}\text { storage } \\
\text { duration }\end{array}$ & $\begin{array}{c}\text { No. of } \\
\text { donors }\end{array}$ & $\begin{array}{c}\text { No. of } \\
\text { depletions }\end{array}$ \\
\hline \multirow{2}{*}{ stage 1} & $\mathrm{~EB}$ vs $\mathrm{EEB}$ vs $\mathrm{EEB}+\mathrm{C}$ vs & \multirow{2}{*}{ glass } & 2 days & \multirow{2}{*}{6} & \multirow{2}{*}{4} \\
\hline & $\mathrm{EEB}+\mathrm{T} 20$ & & 21 days & & \\
\hline stage 2 & $\mathrm{~EB}$ vs $\mathrm{EEB}+\mathrm{T} 20$ & banknote & 7 days & 8 & 1 \\
\hline
\end{tabular}

The International Fingerprint Research Group (IFRG) guidelines were followed in terms of the number of donors, collection of fingermarks, depletion series and the split-mark approach [30]. Substrates for deposition of fingermarks included glass slides (25.4 x $76.2 \mathrm{~mm}, 1.0-1.2 \mathrm{~mm}$ thick, clear plain ground edges, Sail Brand, Catalogue No 7101) and circulated and uncirculated 5 Australian dollars (AUD) polymer banknotes. Twelve donors, both male and female, aged between 20-60 years, were asked not to wash their hands or touch chemicals for at least $30 \mathrm{~min}$ before fingermark donation. All fingertips were rubbed together before fingermark deposition to uniformly distribute skin secretion. Fingermark samples were collected by having donors touch the substrates and hold their fingers on them for approximately 4 seconds. Split fingermarks in depletion series were used in this comparative testing. See Supplementary Data, Section A4.1 and Fig. A5 for more explanation regarding split marks and depletion series.

All fingermark samples were stored in an office environment away from sunlight without any further light protection. The temperature $\left(20-23{ }^{\circ} \mathrm{C}\right)$ and relative humidity (28-67 \%) were monitored using a Digitech QP-6013 data logger throughout storage.

Powder dusting was applied using soft natural camel hair brushes (Model Master, 3/8", USA) [16, 31]. A swirling movement of the brush was used when applying the powders. The substrates were tapped to remove excess particles.

The developed latent fingermarks were photographed in a dark room using a modified digital Canon camera (EOS 40D, Canon, Japan) equipped with an RM90 IR long-pass filter, which cuts off transmission of radiation shorter than approximately $900 \mathrm{~nm}$. The aperture and shutter speed for each photo were 
chosen to enhance the contrast and visibility of the developed fingermarks and are provided under each Figure (see Supplementary Data, Section A2 for more photography details). Prepared powders and developed fingermarks on various substrates were illuminated with a forensic light source (Polilight PL500, Rofin, Australia).

\section{Stage 1: comparison between coarse and exfoliated particles}

Four depletions of natural split fingermarks from 6 donors were deposited on glass slides and stored for 2 and 21 days. These sets of fingermarks are called 2day old and 21-day old hereafter. The latent fingermarks were dusted with EB, EEB, EEB+C, and EEB+T20 powders. Fig. 3 (a) and (b) illustrate two representatives of the developed fingermarks (see Supplementary Data, Fig. A6 and Fig. A7 for the entire set). From left to right, the split marks with the same secretion were treated with $\mathrm{EB}, \mathrm{EEB}, \mathrm{EEB}+\mathrm{C}$, and $\mathrm{EEB}+\mathrm{T} 20$ powders. The majority of the fingermarks treated by EB and EEB+T20 powders presented higher luminescence intensity under the same illumination and photography conditions. This was expected in the case of EB-developed marks since the exfoliation of the particles predictably decreases the luminescence (Fig. 1 (a1d)). However, EEB+T20-developed fingermarks were brighter and more distinct possibly because of the attachment of a greater number of Tween ${ }^{\circledR} 20$-coated particles compared to the uncoated and CTAB-coated particles. Fig. 3 (c) tallies the number of treated fingermarks with the highest ridge details for each dusting powder. It should be noted that the performance of the powders was compared per depletion in which the marks contain the same secretion (see Supplementary Data, Section A4.2 and Table A1 for more details). As per Fig. 3 (c), EEB+T20 powder developed the greatest number of higher quality fingermarks in both the 2-day old and 21-day old sets of experiments. Uncoated exfoliated powders presented the poorest results, particularly in the case of aged fingermarks which lost volatiles over time. This highlights the importance of coating the particles to increase their attachment to the secretion. An explanation for this observation could be the adhesion of more lipophilic-coated 
EEB particles to the remained oily components of the residue through lipophilic interactions [32-34].

Therefore, EEB+T20 powder was considered the most enhanced fingermark developer and was utilised in stage 2.

(a) 2-day old
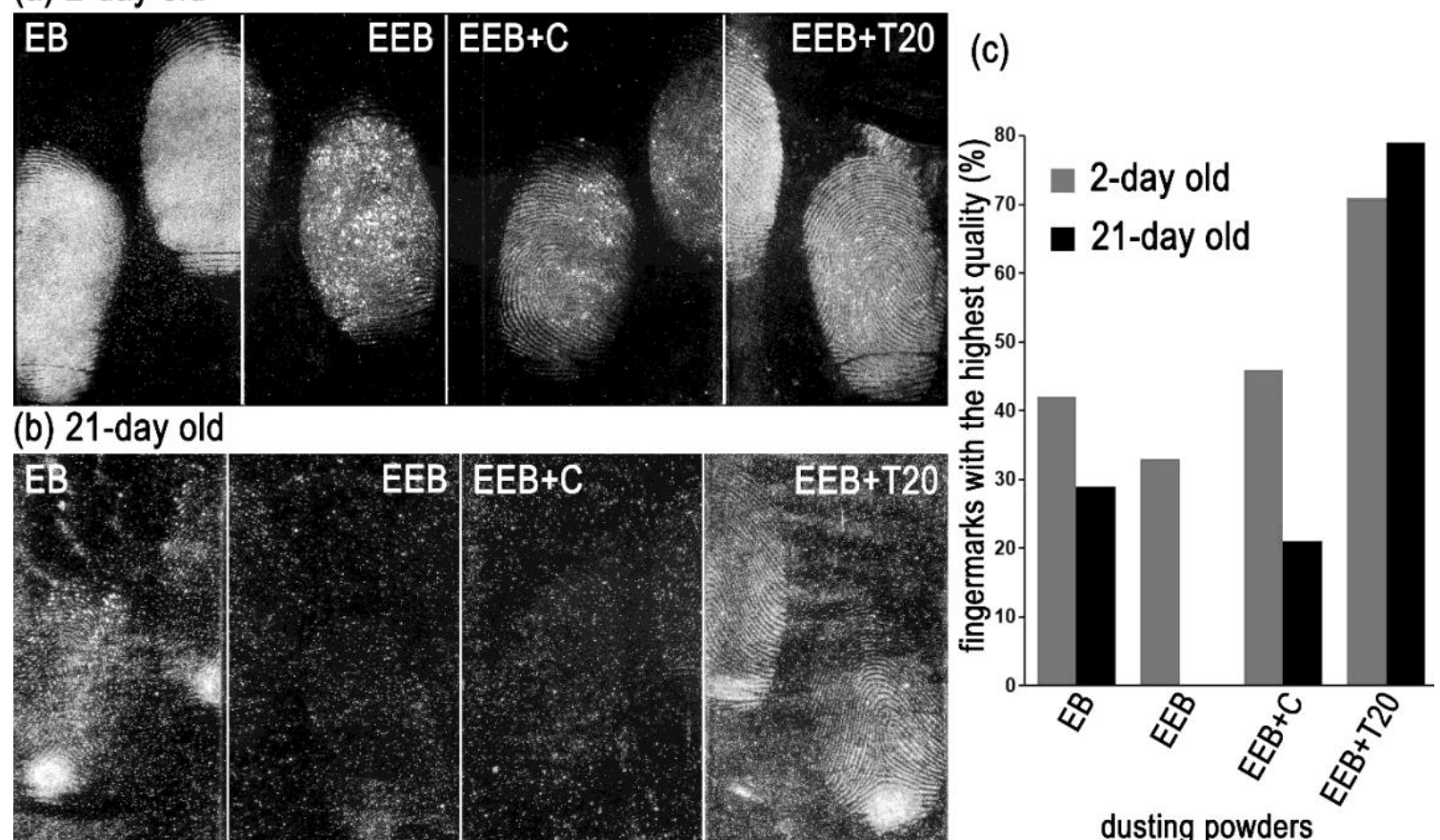

Fig. 3 Comparison between EB, EEB, EEB+C and EEB+T20: (a) 2-day old and (b) 21-day old natural split fingermarks on glass slides photographed with Canon camera (excitation: $590 \mathrm{~nm}$, IR long-pass filter, f-stop: f/6.3, exposure times: $5 \mathrm{~s}$ for 2 -day old and $15 \mathrm{~s}$ for 21 -day old). (c) the percentage of the developed fingermarks with the highest quality for each powder; $n=24$ (the total number of depletion series).

Stage 2: comparison between $E B$ and EEB+T20

In this stage, the capability of the Tween ${ }^{\circledR} 20$-coated EEB as the most successful fingermark developer was compared with the commercial powder (EB) in developing natural fingermarks on a realistic and challenging semi-porous surface, namely colourful polymer banknotes, as a common multi-coloured and multi-patterned substrate.

Natural split fingermarks from 8 donors were deposited on 5 AUD notes. As per previous investigations, the Queen's portrait is a challenging area on the note 
because of its rough texture and pattern similar to the fingermark ridges. Therefore, split marks were deposited on the Queen's portrait, stored for 7 days, and treated with EB and EEB+T20 powders. Fig. 4 shows a representative image of the developed fingermarks (see Supplementary Data, Fig. A8 for the entire set). Because of the faint visible appearance of the dusted fingermarks on the visible image, a digital fingermark icon was overlaid to indicate general location of the fingermark deposition. The advantage of using NIR luminescent powders for the highly patterned substrate is apparent in the images. The background interference was effectively eliminated. For the majority of treated split fingermarks, the half developed with EEB+T20 demonstrated less background interference, higher contrast, and clearer ridge details (Supplementary Data, Fig. A8).

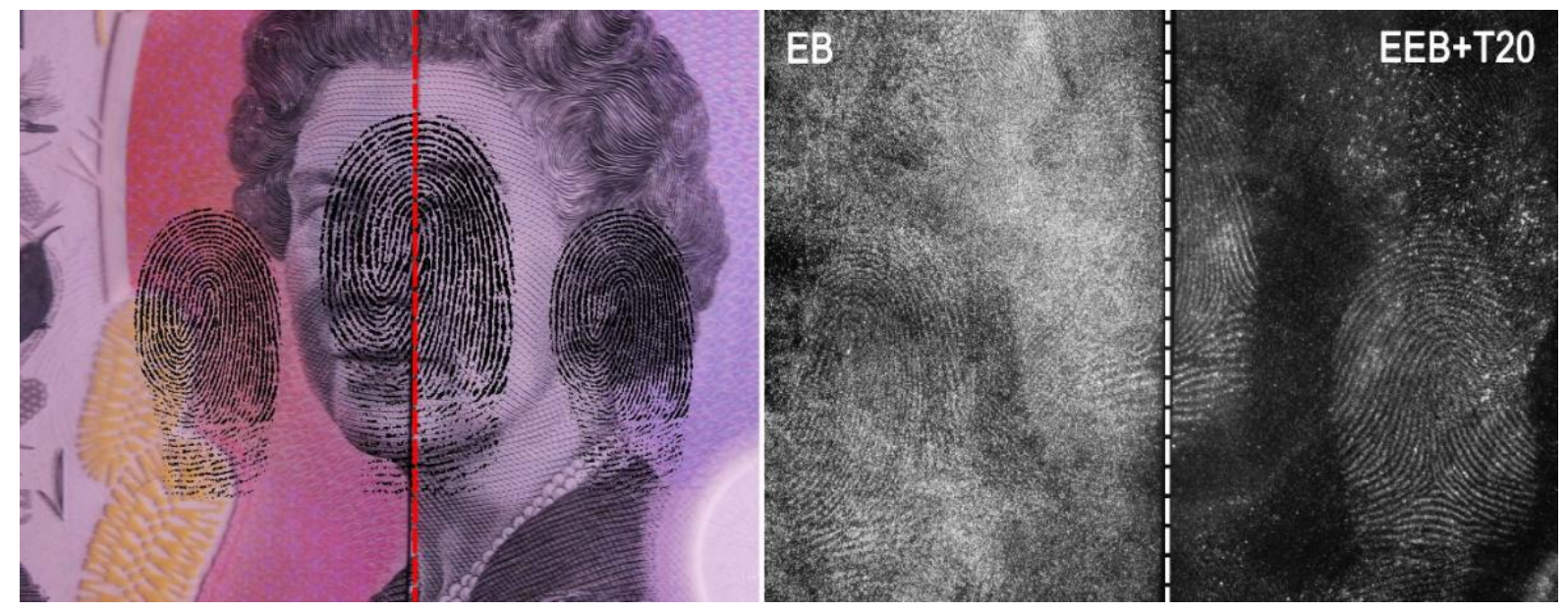

Fig. 4 Comparison between EB and EEB+T20: 7-day old natural split fingermarks on 5 AUD note photographed with Canon camera (excitation: $590 \mathrm{~nm}$, IR long-pass filter, f-stop: f/6.3, exposure time: $0.6 \mathrm{~s}$ ). 5 AUD note on the left was provided to show general location rather than exact location.

\section{Conclusion}

Utilising methanol instead of water facilitated liquid-exfoliation of highly durable layered commercial EB pigment particles at room temperature. This new approach made the particle preparation method safer, simpler, and less expensive than exfoliation in hot water. The particles were also coated with CTAB or Tween ${ }^{2} 20$ during the preparation, rendering them more compatible 
with lipophilic latent fingermarks, especially aged prints that have lost much of the water phase. Comprehensive experiments were conducted to investigate the performance of coated exfoliated particles for the detection of latent fingermarks. Tween ${ }^{\circledR} 20$-coated EEB demonstrated the highest contrast among EB, uncoated EEB, and CTAB-coated EEB, especially in cases of aged fingermarks. This is due to its desired characteristics including particle size, luminescence intensity, and hydrophobic surface modification. It also outperformed the commercial pigment for challenging substrates.

\section{Acknowledgements}

The authors thank all fingermark donors for their cooperation. We thank the Reserve Bank of Australia for supplying the banknotes in this study and the associated permission to damage the notes in the course of the research. This research has been conducted following the Curtin University Human Research Ethics Committee (Approval Number HRE2016-0252).

\section{CRediT Author Statement}

Sorour Shahbazi: Conceptualisation, Methodology, Investigation, Formal analysis, Writing - Original Draft, Writing - Review \& Editing.

John V. Goodpaster: Conceptualisation, Methodology, Writing - Review \& Editing.

Gregory D. Smith: Conceptualization, Methodology, Writing - Review \& Editing.

Thomas Becker: Conceptualisation, Methodology, Writing - Review \& Editing.

Simon W. Lewis: Conceptualisation, Supervision, Project administration, Methodology Resources, Writing - Review \& Editing.

\section{Appendix A. Supplementary data}




\section{Supplementary data is provided}

\section{References}

[1] J. Lee, M.M. Joullié, Novel design and approach to latent fingerprint detection on paper using a 1,2-indanedione-based bi-functional reagent, Tetrahedron Letters, 56 (2015) 3378-3381. https://doi.org/10.1016/j.tetlet.2014.12.109

[2] C. Lennard, Fingerprint detection: future prospects, Australian Journal of Forensic Sciences, 39 (2007) 73-80. https://doi.org/10.1080/00450610701650039

[3] M.J. Choi, A.M. McDonagh, P. Maynard, C. Roux, Metal-containing nanoparticles and nanostructured particles in fingermark detection, Forensic Science International, 179 (2008) 87-97. https://doi.org/10.1016/j.forsciint.2008.04.027

[4] S. Moret, A. Bécue, C. Champod, Nanoparticles for fingermark detection: an insight into the reaction mechanism, Nanotechnology, 25 (2014) 425502. https://doi.org/10.1088/0957$\underline{4484 / 25 / 42 / 425502}$

[5] A. Becue, A.A. Cantú, Fingermark detection using nanoparticles, in: S.R. Robert (Ed.) Lee and Gaensslen's Advances in Fingerprint Technology, CRC Press LLC, Miami, 2012, pp. 307-380.

[6] A. Girod, R. Ramotowski, C. Weyermann, Composition of fingermark residue: a qualitative and quantitative review, Forensic Science International, 223 (2012) 10-24.

https://doi.org/10.1016/j.forsciint.2012.05.018

[7] M. Stoilovic, C. Lennard, NCFS workshop manual: fingermark detection \& enhancement, $6^{\text {th }}$ ed., National Centre for Forensic Studies, Canberra, 2012.

[8] P. Maynard, J. Jenkins, C. Edey, G. Payne, C. Lennard, A. McDonagh, C. Roux, Near infrared imaging for the improved detection of fingermarks on difficult surfaces, Australian Journal of Forensic Sciences, 41 (2009) 43-62. https://doi.org/10.1080/00450610802172248

[9] S. Shahbazi, T. Becker, G. Jia, S.W. Lewis, Luminescent nanostructures for the detection of latent fingermarks: A review, Wiley Interdisciplinary Reviews: Forensic Science, (2021) e1440. https://doi.org/10.1002/wfs2.1440

[10] R.S.P. King, P.M. Hallett, D. Foster, NIR-NIR fluorescence: A new genre of fingermark visualisation techniques, Forensic Science International, 262 (2016) e28-e33. https://doi.org/10.1016/j.forsciint.2016.03.037

[11] P. Bianchetti, F. Talarico, M.G. Vigliano, M.F. Ali, Production and characterization of Egyptian blue and Egyptian green frit, Journal of Cultural Heritage, 1 (2000) 179-188. https://doi.org/10.1016/S1296-2074(00)00165-5

[12] G. Accorsi, G. Verri, M. Bolognesi, N. Armaroli, C. Clementi, C. Miliani, A. Romani, The exceptional near-infrared luminescence properties of cuprorivaite (Egyptian blue), Chemical Communications, (2009) 3392-3394. https://doi.org/10.1039/B902563D

[13] G. Verri, The spatially resolved characterisation of Egyptian blue, Han blue and Han purple by photo-induced luminescence digital imaging, Analytical and Bioanalytical Chemistry, 394 (2009) 1011-1021. https://doi.org/10.1007/s00216-009-2693-0

[14] B. Errington, G. Lawson, S.W. Lewis, G.D. Smith, Micronised Egyptian blue pigment: a novel near-infrared luminescent fingerprint dusting powder, Dyes and Pigments, 132 (2016) 310 315. https://doi.org/10.1016/j.dyepig.2016.05.008 
[15] D. Johnson-McDaniel, C.A. Barrett, A. Sharafi, T.T. Salguero, Nanoscience of an ancient pigment, Journal of the American Chemical Society, 135 (2013) 1677-1679.

https://doi.org/10.1021/ja310587c

[16] S. Shahbazi, J.V. Goodpaster, G.D. Smith, T. Becker, S.W. Lewis, Preparation, characterization, and application of a lipophilic coated exfoliated Egyptian blue for near-infrared luminescent latent fingermark detection, Forensic Chemistry, 18 (2020) 100208. https://doi.org/10.1016/i.forc.2019.100208

[17] B. Yamashita, M. French, Latent print development, in: A. McRoberts (Ed.) Fingerprint Source Book, Createspace Independent Publishing Platform, Washington, 2011, pp. 7-67.

[18] S. Bleay, V. Sears, R. Downham, H. Bandey, A. Gibson, V. Bowman, L. Fitzgerald, T. Ciuksza, J. Ramadani, C. Selway, Fingerprint source book, $2^{\text {nd }}$ ed., Home Office Centre for Applied Science and Technology, UK, 2018.

[19] T. Kent, Manual of fingerprint development techniques, Home Office, Sandridge, 1998.

[20] V. Nicolosi, M. Chhowalla, M.G. Kanatzidis, M.S. Strano, J.N. Coleman, Liquid exfoliation of layered materials, Science, 340 (2013) 1226419. https://doi.org/10.1126/science.1226419

[21] C. Backes, T.M. Higgins, A. Kelly, C. Boland, A. Harvey, D. Hanlon, J.N. Coleman, Guidelines for exfoliation, characterization and processing of layered materials produced by liquid exfoliation, Chemistry of Materials, 29 (2017) 243-255.

https://doi.org/10.1021/acs.chemmater.6b03335

[22] M.J. Choi, K.E. McBean, P.H.R. Ng, A.M. McDonagh, P.J. Maynard, C. Lennard, C. Roux, An evaluation of nanostructured zinc oxide as a fluorescent powder for fingerprint detection, Journal of Materials Science, 43 (2008) 732-737. https://doi.org/10.1007/s10853-007-2178-5

[23] A. Becue, A. Scoundrianos, S. Moret, Detection of fingermarks by colloidal gold (MMD/SMD) - beyond the pH 3 limit, Forensic Science International, 219 (2012) 39-49.

https://doi.org/10.1016/j.forsciint.2011.11.024

[24] T.G. Newland, S. Moret, A. Bécue, S.W. Lewis, Further investigations into the single metal deposition (SMD II) technique for the detection of latent fingermarks, Forensic Science International, 268 (2016) 62-72. https://doi.org/10.1016/j.forsciint.2016.09.004

[25] M. Tite, M. Bimson, M. Cowell, The technology of Eygptian blue, in: Early Vitreous Materials, 1987, pp. 19-47.

[26] B. Udvardi, I.J. Kovács, T. Fancsik, P. Kónya, M. Bátori, F. Stercel, G. Falus, Z. Szalai, Effects of particle size on the attenuated total reflection spectrum of minerals, Applied Spectroscopy, 71 (2017) 1157-1168. https://doi.org/10.1177/0003702816670914

[27] C.F. Bohren, D.R. Huffman, Absorption and scattering of light by small particles, John Wiley \& Sons, 2008.

[28] C. Koike, Y. Imai, H. Chihara, H. Suto, K. Murata, A. Tsuchiyama, S. Tachibana, S. Ohara, Effects of forsterite grain shape on infrared spectra, The Astrophysical Journal, 709 (2010) 983. https://doi.org10.1088/0004-637X/709/2/983

[29] P. Kristova, L.J. Hopkinson, K.J. Rutt, The effect of the particle size on the fundamental vibrations of the $\left[\mathrm{CO}_{3}{ }^{2-}\right]$ anion in calcite, The Journal of Physical Chemistry A, 119 (2015) 4891 4897. https://doi.org/10.1021/acs.jpca.5b02942 
[30] IFRG, Guidelines for the assessment of fingermark detection techniques, Journal of Forensic Identification, 64 (2014) 174-200. https://ips-labs.unil.ch/ifrg/wp-content/uploads/2014/06/IFRGResearch-Guidelines-v1-Jan-2014.pdf

[31] B. Errington, An alternative method for the detection of latent fingermarks using NIR luminescence imaging, in: Department of Chemistry, Curtin University, 2013, pp. 56.

[32] S. Chadwick, P. Maynard, P. Kirkbride, C. Lennard, A. McDonagh, X. Spindler, C. Roux, Styryl dye coated metal oxide powders for the detection of latent fingermarks on non-porous surfaces, Forensic Science International, 219 (2012) 208-214.

https://doi.org/10.1016/j.forsciint.2012.01.006

[33] N.E. Archer, Y. Charles, J.A. Elliott, S. Jickells, Changes in the lipid composition of latent fingerprint residue with time after deposition on a surface, Forensic Science International, 154 (2005) 224-239. https://doi.org/10.1016/j.forsciint.2004.09.120

[34] A.A. Frick, G. Chidlow, S.W. Lewis, W. van Bronswijk, Investigations into the initial composition of latent fingermark lipids by gas chromatography-mass spectrometry, Forensic Science International, 254 (2015) 133-147. http://dx.doi.org/10.1016/j.forsciint.2015.06.032 


\section{SUPPLEMENTARY DATA}

Studies into exfoliation and coating of Egyptian blue in methanol for application to the detection of latent fingermarks

\section{A1. Dusting powder preparation}

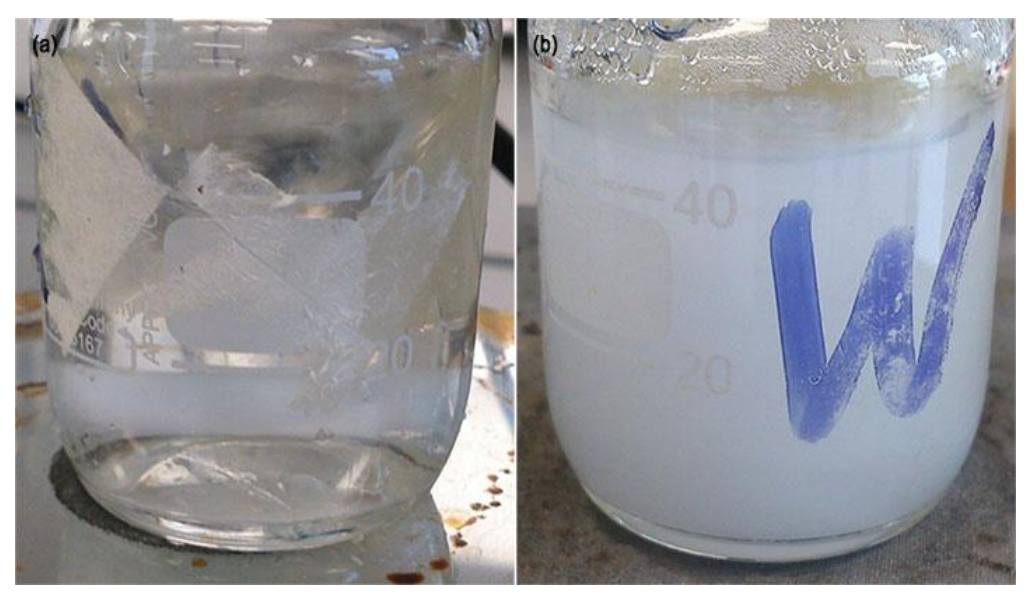

Fig. A1. Photographs CTAB stirred in (a) methanol and (b) water at room temperature.

\section{A2. Photography specification}

The digital Canon camera was equipped with a Canon EFS 18-55 mm lens. The camera was modified to photograph in the infrared (IR) region. As part of the modification, the camera's internal IR blocking filter, which normally reduces the natural sensitivity of charge-coupled device (CCD) and complementary metal oxide semiconductor (CMOS) sensor to IR radiation, was removed. The camera was installed on a Firenze mini repro stand in a darkened room for the respective imaging. The camera was connected to a desktop computer running EOS Utility 2 software (version 2.14.20.0) to use the live view and remote-control functions of the camera. 

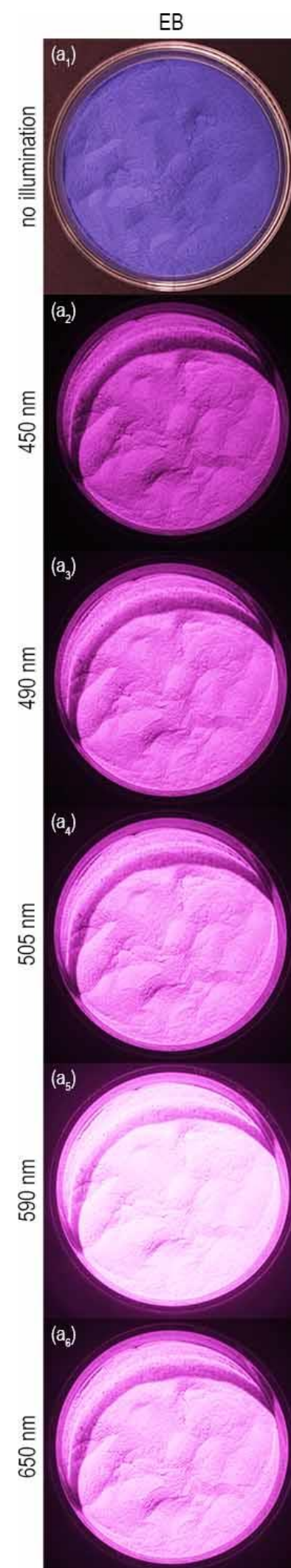

$\left(b_{3}\right)$

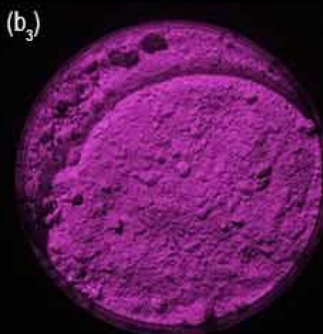

$\left(b_{4}\right)$

EEB

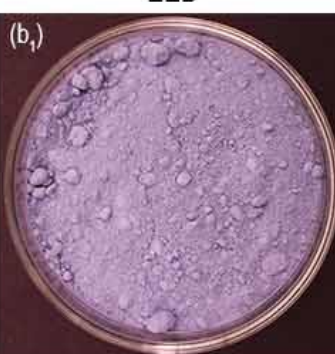

$\left(b_{2}\right)$

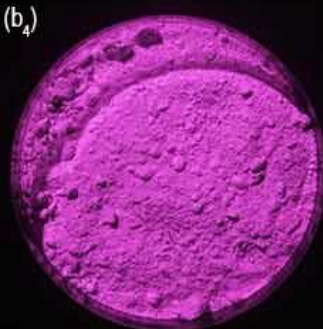

$\left(\mathbf{b}_{5}\right)$

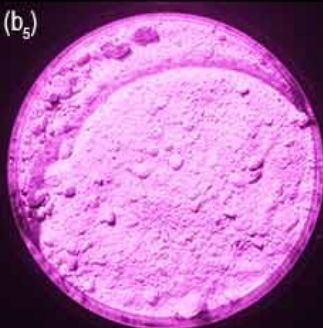

$\left(b_{6}\right)$

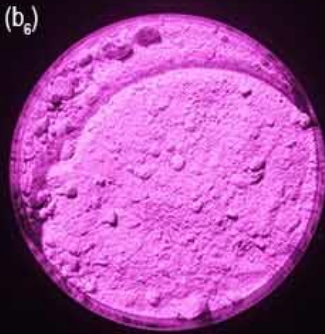

$\mathrm{EEB}+\mathrm{C}$

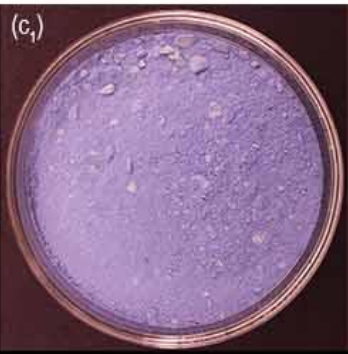

$\left(c_{2}\right)$

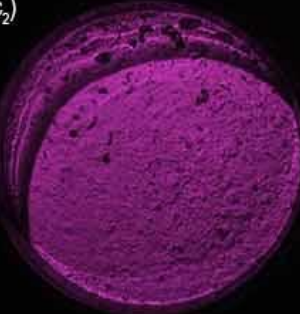

$\left(c_{3}\right)$

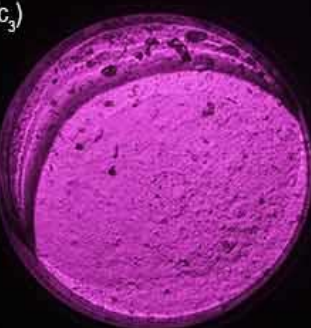

$\left(c_{4}\right)$

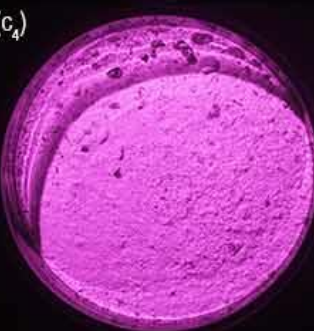

(c)

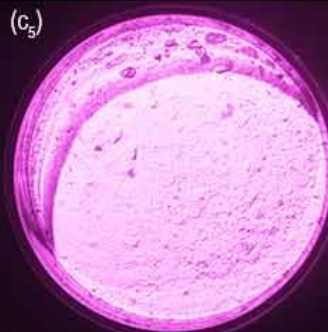

(c)

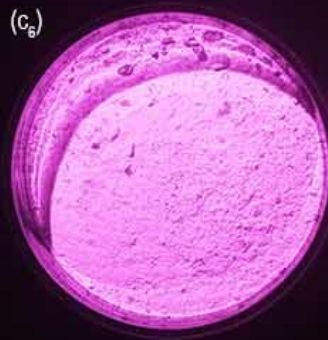

$\mathrm{EEB}+\mathrm{T} 20$

(d)

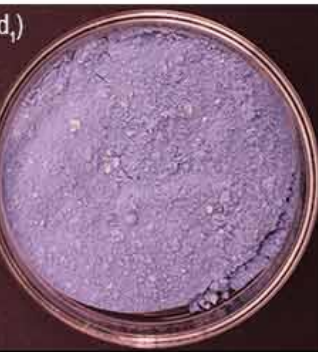

$\left(d_{2}\right)$

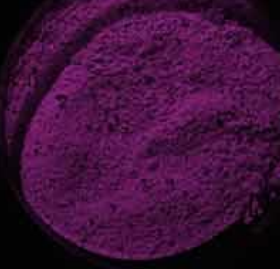

$\left(d_{3}\right)$

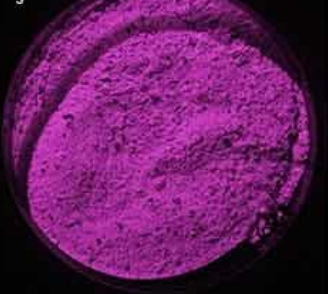

(d)

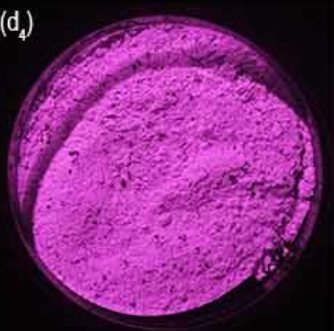

(d)

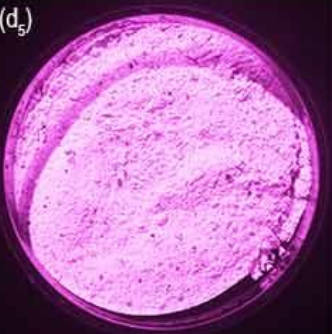

(d)

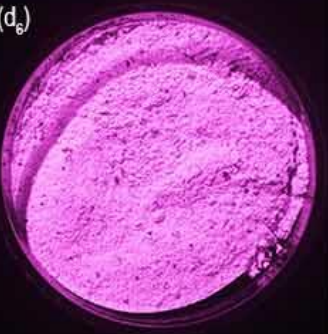

Fig. A2. Photographs of (a) EB, (b) EEB, (c) EEB+C and (d) EEB+T20 powders photographed by Canon camera under $\left(\mathrm{a}_{1}-\mathrm{d}_{1}\right)$ ambient lighting (f-stop: $\mathrm{f} / 6.3$, exposure time: $1 / 5 \mathrm{~s}$ ) and illumination at $\left(\mathrm{a}_{2}-\mathrm{d}_{2}\right) 450 \mathrm{~nm},\left(\mathrm{a}_{3}-\mathrm{d}_{3}\right) 490 \mathrm{~nm},\left(\mathrm{a}_{4}-\mathrm{d}_{4}\right) 505 \mathrm{~nm},\left(\mathrm{a}_{5}-\mathrm{d}_{5}\right) 590 \mathrm{~nm},\left(\mathrm{a}_{6}-\mathrm{d}_{6}\right) 650 \mathrm{~nm}$ (IR long-pass filter, f-stop: f/6.3, exposure time: $1 / 10 \mathrm{~s}$ ). Brightness of the image was increased by $100 \%$. 


\section{A3. Infrared spectroscopy}

FTIR-ATR spectroscopy was used to collecting MIR absorption spectra to study the chemical bonding of the powders. The peak intensities of the absorption spectra were also studied to compare the particle size of the particles. Several studies previously reported that with a decrease in the particle size, the peak intensity increased [1-4]. In ATR, an absorption spectrum is obtained using reflected IR radiation collected after several internal reflections occur between the interface of the sample and the crystal with high $\mathrm{RI}$ relative to the sample (evanescent wave). In this case, the beam extends only a small distance (0.5-2 $\mu \mathrm{m})$ into the sample. Therefore, the more contact area gives a better signal due to decreased background (Equation 1) [1]. Smaller particles could be compacted more tightly and fill the voids between them to increase this contact area and therefore increase absorption [1].

\section{Equation 1}

$$
d p=\frac{\lambda}{2 \pi \sqrt{\sin ^{2} \theta-\left(n_{2} / n_{1}\right)^{2}}}
$$

dp: penetration depth of the IR light

$\lambda$ : wavelength of the IR light

$\theta:$ the angle of incidence of the IR light

$n_{2:}$ average $R I$ of the sample

$n_{1}$ : the internal reflection element

Nicolet spectrometer (Nicolet iS50, ThermoFisher Scientific, USA) was used to study chemical bonding in this study. The instrument equipped with a singlebounce ATR module (diamond crystal with RI $n_{\text {Diamond }}=2.4$ and depth of penetration of $1.66 \mu \mathrm{m}$ (at $\left.45^{\circ}, 1000 \mathrm{~cm}^{-1}\right)$, tungsten-halogen white light source, $\mathrm{KBr}$ beamsplitter, and deuterated triglycine sulfate (DTGS) detector. Spectra were recorded over the range of $4000-400 \mathrm{~cm}^{-1}$. The spectral resolution was $4 \mathrm{~cm}^{-1}$ and scan velocity was $0.4747 \mathrm{~cm} / \mathrm{s}$. For solid-state samples (powder), the spectrometer was equipped with a pressure arm that was used to maintain a constant contact force between the sample and the diamond sampling crystal. For liquid samples, one drop of the sample was placed on the diamond sampling 
crystal. OPUS software (version 7.0 Build: 7, 0, 129 20111219) was used to analyse the data.

As per previous reports, $\mathrm{EB}$ is made of several layers of tetrasilicates and $\mathrm{CuO}_{4}$ squares separated by $\mathrm{Cu}^{2+}$ ions [5-8]. The chemical structure of $\mathrm{EB}$ is shown as an inset in Fig. A3 (a) [5-8]. Characteristic peaks of EB between $1230 \mathrm{~cm}^{-1}$ and $420 \mathrm{~cm}^{-1}$ can be assigned to symmetrical and asymmetrical Si-O-Si stretching (Table in Fig. A3) [9-12].

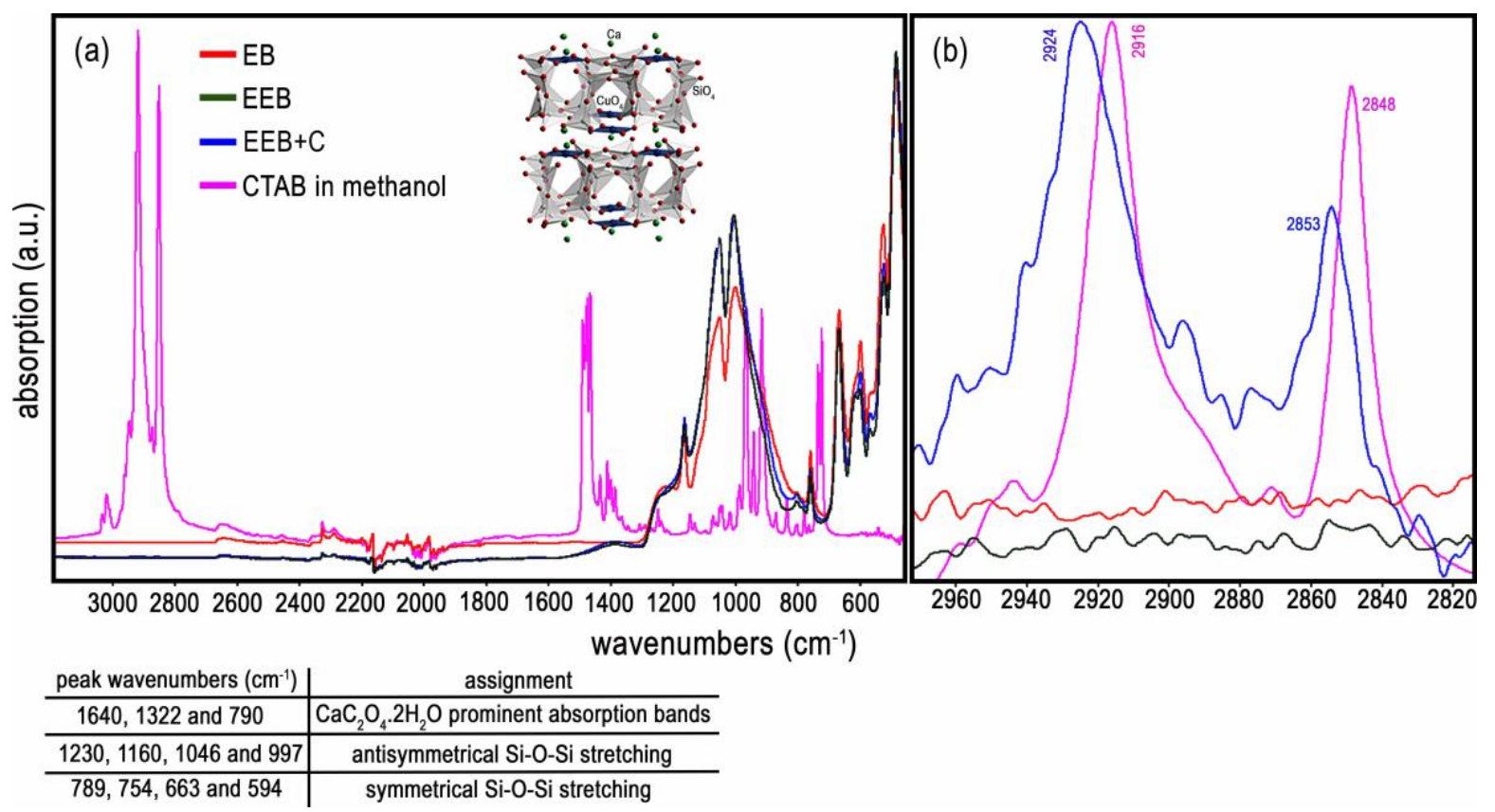

Fig. A3. (a) MIR spectra of EB before and after exfoliation in methanol without and with CTAB as well as CTAB in methanol. (b) Spectra in narrower ranges of wavenumbers. Table shows the vibrational frequencies observed in MIR spectra. Inset in (a) shows the chemical structure of EB [8]. 


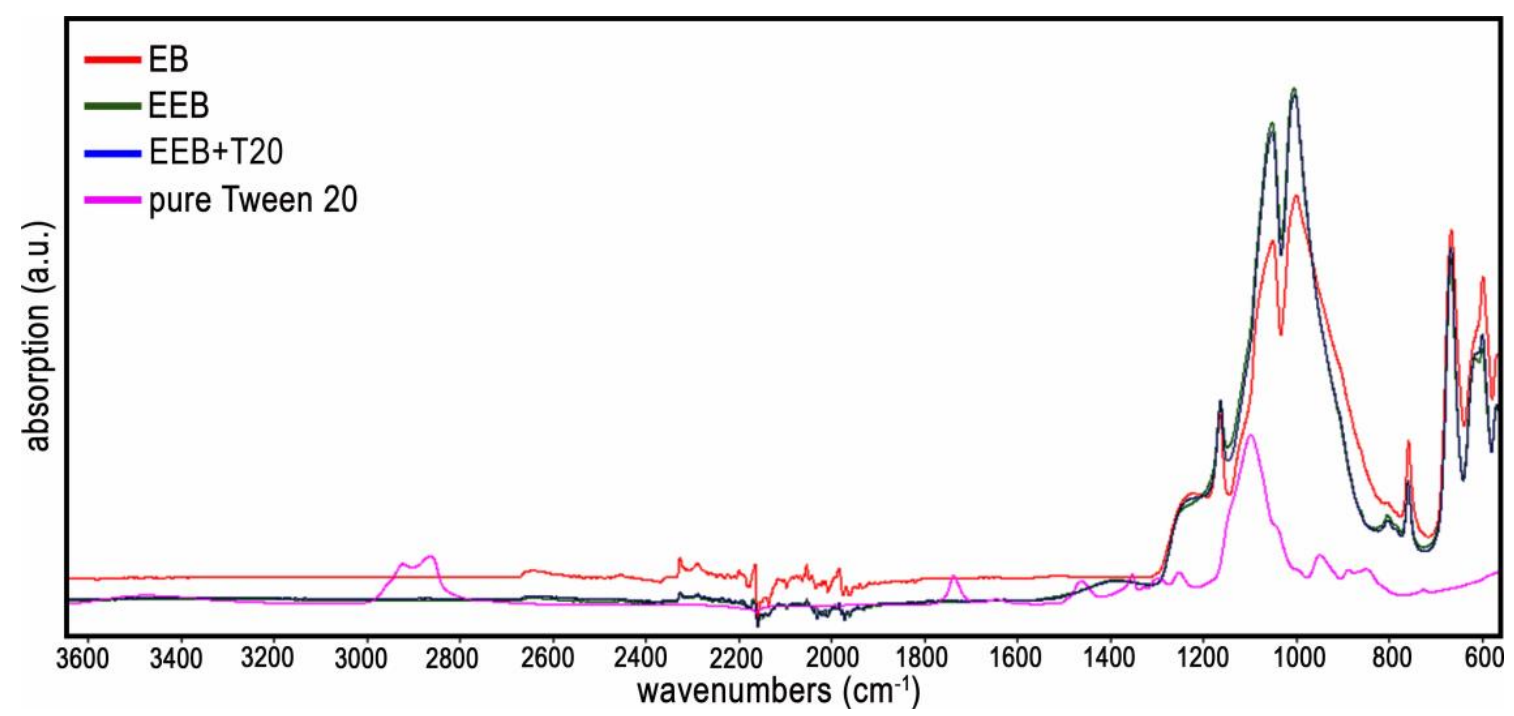

Fig. A4. MIR spectra of EB before and after exfoliation in methanol without and with Tween ${ }^{\circledR} 20$ as well as pure Tween ${ }^{\circledR} 20$.

\section{A4. Fingermarks development}

\section{A4.1. Split fingermarks and depletion series}

Fingermark depletion series to assess the sensitivity of the method were prepared by asking donors to press the same fingers sequentially without any delay between each deposition on the substrate to produce a series of increasingly weaker secretion residues.

To collect split fingermarks, two substrates were attached side by side and three middle fingers were used for deposition. Permission was granted by the Reserve Bank of Australia to conduct the described experiments on the banknotes, including cutting notes where necessary (Fig. A5). 


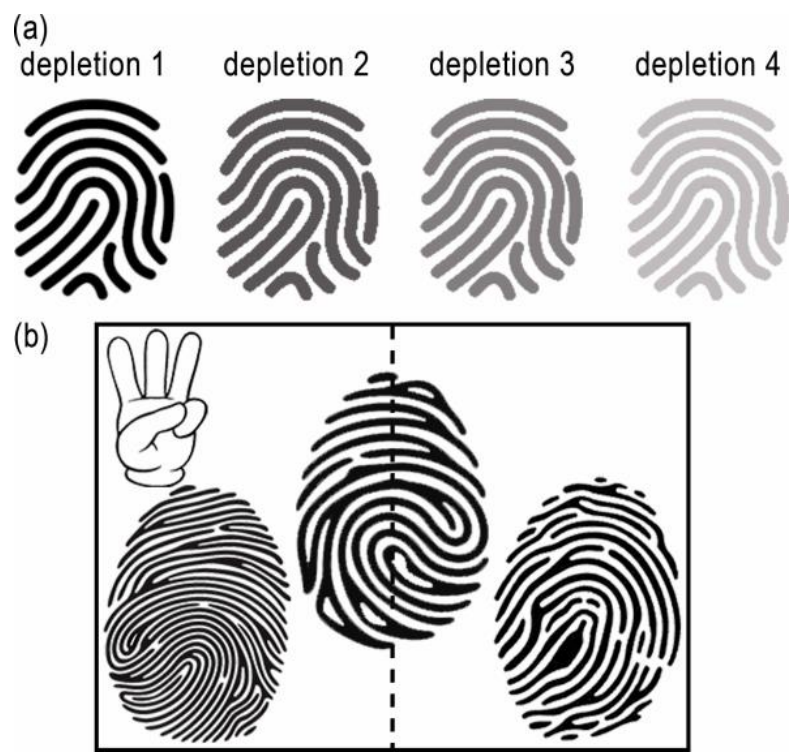

Fig. A5. Schematic of (a) depletion series and (b) split fingermarks from three middle fingers. 


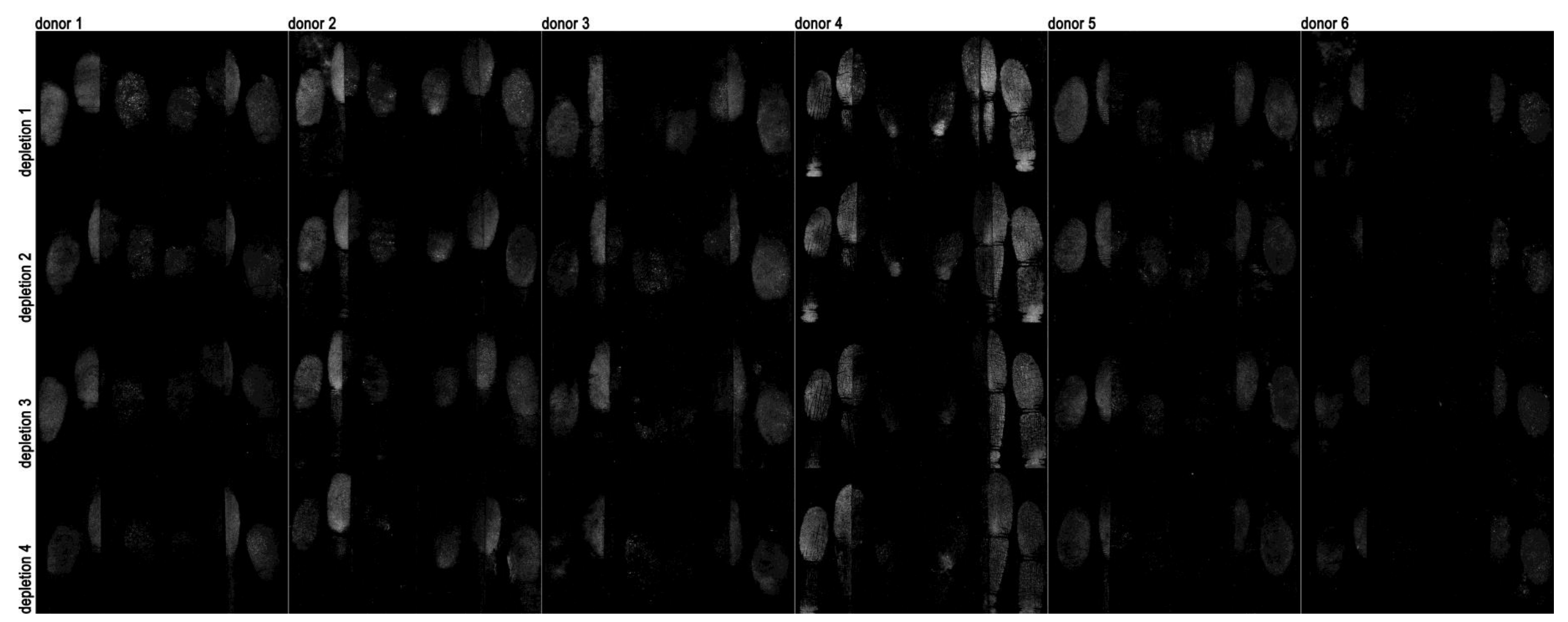

Fig. A6. 4 depletions of natural split fingermarks from 6 donors deposited on glass slides, stored for 2 days, dusted with EB, EEB, EEB+C and EEB+T20 (from left) and photographed with Canon camera (excitation: $590 \mathrm{~nm}$, IR long-pass filter, f-stop: f/6.3, exposure time: $1 \mathrm{~s}$ ). 


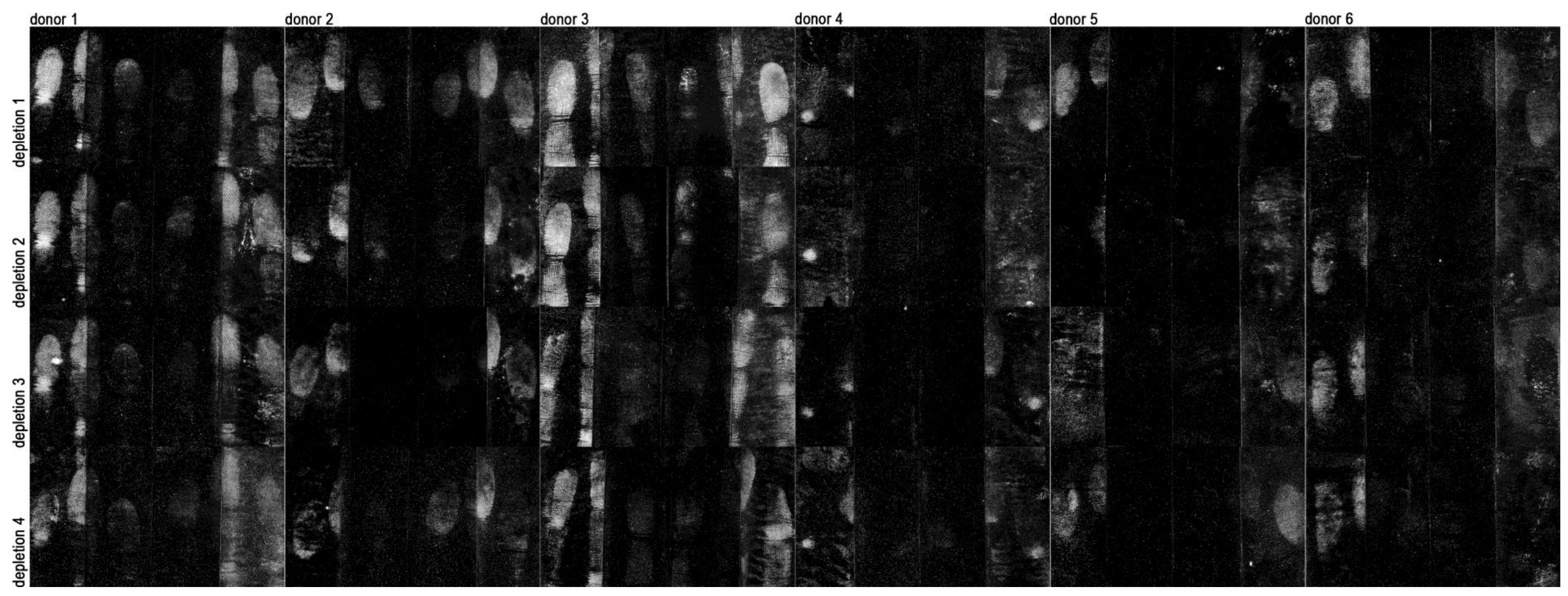

Fig. A7. 4 depletions of natural split fingermarks from 6 donors deposited on glass slides, stored for 21 days, dusted with EB, EEB, EEB+C and EEB+T20 (from left) and photographed with Canon camera (excitation: $590 \mathrm{~nm}$, IR long-pass filter, f-stop: f/6.3, exposure time: $8 \mathrm{~s}$ ). 


\section{A4.2. Statistic comparison}

To reach a statistic comparison, the best developer was selected based on the ridge clarity in each depletion with the same secretion (Table A1). For example, according to Table A1, for the $3^{\text {rd }}$ depletion of donor 5 in 2-day old set, EEB+T20 developed the fingermarks with the highest ridge detail. It should be noted that if more than one powder developed almost the same degree of quality, all of them were selected. For example, for the $1^{\text {st }}$ depletion of donor 4 in 2 -day old set, all powders presented almost the same degree of ridge details. The percentage was calculated based on the total number of depletion series ( 6 donors X 4 depletions $=24$ ).

Table A1. Demonstration of the performance of powders for the development of the highest quality of fingermark.

\begin{tabular}{|c|c|c|c|c|c|c|c|c|c|c|c|c|c|c|c|c|c|c|c|c|c|c|c|c|c|}
\hline \multicolumn{26}{|c|}{ 2-day old fingermarks } \\
\hline & \multicolumn{4}{|c|}{ donor 1} & \multicolumn{4}{|c|}{ donor 2} & \multicolumn{4}{|c|}{ donor 3} & \multicolumn{4}{|c|}{ donor4 } & \multicolumn{4}{|c|}{ donor 5} & \multicolumn{4}{|c|}{ donor6 } & \multirow[b]{2}{*}{$\%$} \\
\hline & $\overrightarrow{0}$ & $\stackrel{\stackrel{N}{A}}{ }$ & $\stackrel{m}{\theta}$ & $\stackrel{+}{\oplus}$ & $\vec{\theta}$ & $\stackrel{\sim}{\mathrm{A}}$ & $\stackrel{m}{\rho}$ & $\stackrel{+}{\theta}$ & $\vec{\theta}$ & $\stackrel{\stackrel{N}{A}}{ }$ & $\stackrel{m}{\oplus}$ & $\stackrel{+}{\oplus}$ & $\bar{\theta}$ & $\stackrel{\stackrel{N}{A}}{ }$ & $\stackrel{m}{\rho}$ & $\stackrel{+}{9}$ & $\overrightarrow{0}$ & $\stackrel{\stackrel{N}{A}}{ }$ & $\stackrel{m}{\rho}$ & $\stackrel{\vec{A}}{\oplus}$ & $\bar{\theta}$ & $\stackrel{\stackrel{N}{a}}{ }$ & $\stackrel{m}{\theta}$ & $\stackrel{\vec{\theta}}{\circ}$ & \\
\hline 国 & $\checkmark$ & $\checkmark$ & $\checkmark$ & & & & & $\checkmark$ & & & & & $\sqrt{ }$ & & $\checkmark$ & $\checkmark$ & & & & & $\checkmark$ & $\checkmark$ & $\checkmark$ & & 42 \\
\hline $\begin{array}{l}9 \\
\text { 空 } \\
\end{array}$ & . & & & & & & & & $\checkmark$ & & & & $\checkmark$ & & & $\checkmark$ & & & & $\checkmark$ & $\checkmark$ & $\checkmark$ & $\checkmark$ & $\checkmark$ & 33 \\
\hline 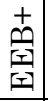 & 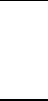 & & & & $\checkmark$ & $\checkmark$ & & & & $\checkmark$ & $\checkmark$ & $\checkmark$ & $\checkmark$ & & & & & & & $\checkmark$ & $\checkmark$ & $\checkmark$ & $\checkmark$ & $\checkmark$ & 46 \\
\hline 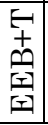 & $\checkmark$ & $\checkmark$ & $\checkmark$ & $\checkmark$ & & & $\checkmark$ & $\checkmark$ & & & & $\checkmark$ & $\checkmark$ & $\checkmark$ & $\checkmark$ & & $\checkmark$ & $\checkmark$ & $\checkmark$ & $\checkmark$ & $\checkmark$ & $\checkmark$ & $\checkmark$ & & 71 \\
\hline \multicolumn{25}{|c|}{ 21-day old fingermarks } & \\
\hline 田 & & $\checkmark$ & $\checkmark$ & & & & & & & & & $\checkmark$ & & & & & $\checkmark$ & $\checkmark$ & & & & & $\checkmark$ & $\checkmark$ & 29 \\
\hline 国 & & & & & & & & & & & & & & & & & & & & & & & & & 0 \\
\hline $\begin{array}{l}+ \\
\text { 堂 } \\
\text { 空 }\end{array}$ & & & & $\checkmark$ & $\checkmark$ & $\checkmark$ & & $\checkmark$ & & & & & & & & & & & $\checkmark$ & & & & & & 21 \\
\hline 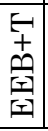 & $\checkmark$ & $\checkmark$ & $\checkmark$ & $\checkmark$ & & $\checkmark$ & $\checkmark$ & $\checkmark$ & $\checkmark$ & $\checkmark$ & $\checkmark$ & & $\checkmark$ & $\checkmark$ & $\checkmark$ & $\checkmark$ & $\checkmark$ & & $\checkmark$ & $\checkmark$ & $\checkmark$ & $\checkmark$ & & & 79 \\
\hline
\end{tabular}

* D: Depletion 


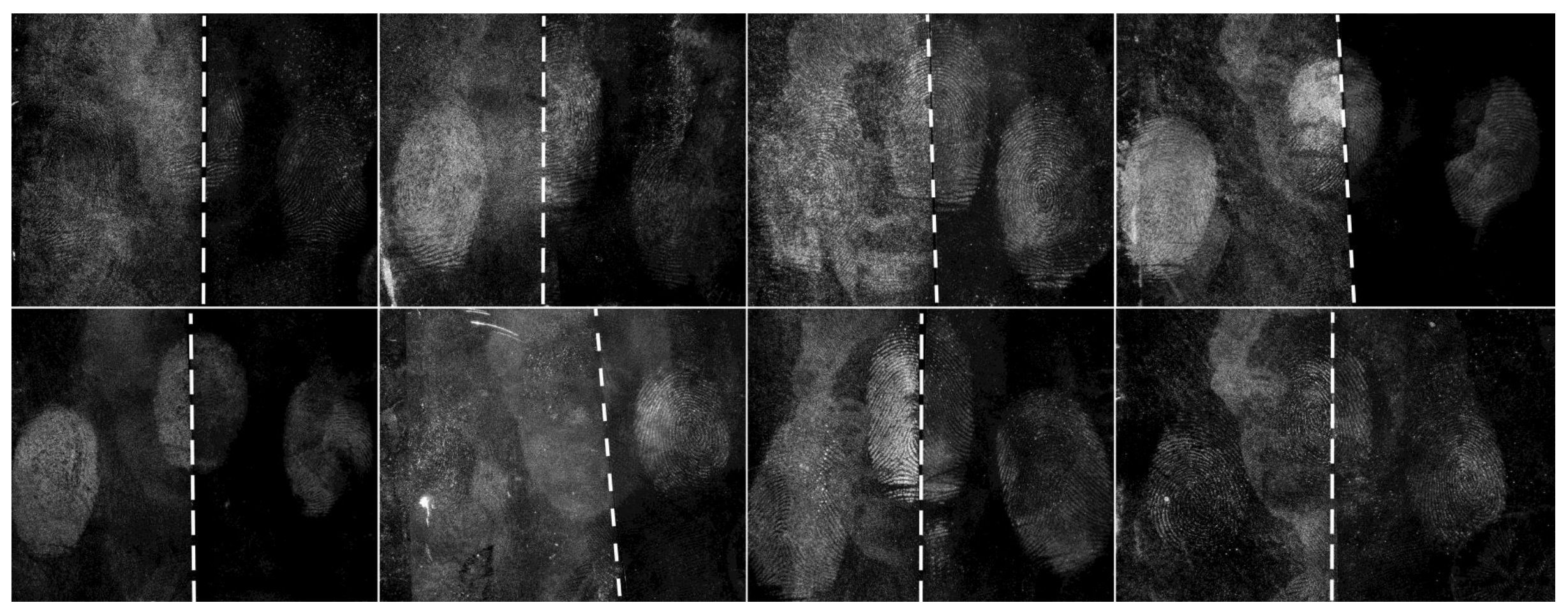

Fig. A8. Natural split fingermarks from 8 donors deposited on 5 AUD note, stored for 7 days, dusted with EB (left) and EEB+T20 (right) and photographed with Canon camera (excitation: $590 \mathrm{~nm}$, IR long-pass filter, f-stop: f/6.3, exposure times: donor 1: 1/3 s donor 2: 1.6 s, donor 3: 1/10 s, donor 4: $5 \mathrm{~s}$, donor 5: 1/5 s, donor 6: $1 \mathrm{~s}$, donor 7: 1/2 s, donor 8: 1/2 s, donor 9: $1 \mathrm{~s}$ ). 


\section{References}

[1] B. Udvardi, I.J. Kovács, T. Fancsik, P. Kónya, M. Bátori, F. Stercel, G. Falus, Z. Szalai, Effects of particle size on the attenuated total reflection spectrum of minerals, Applied Spectroscopy, 71 (2017) 1157-1168. https://doi.org/10.1177/0003702816670914

[2] C.F. Bohren, D.R. Huffman, Absorption and scattering of light by small particles, John Wiley \& Sons, 2008.

[3] C. Koike, Y. Imai, H. Chihara, H. Suto, K. Murata, A. Tsuchiyama, S. Tachibana, S. Ohara, Effects of forsterite grain shape on infrared spectra, The Astrophysical Journal, 709 (2010) 983. https://doi.org 10.1088/0004-637X/709/2/983

[4] P. Kristova, L.J. Hopkinson, K.J. Rutt, The effect of the particle size on the fundamental vibrations of the $\left[\mathrm{CO}_{3}{ }^{2-}\right]$ anion in calcite, The Journal of Physical Chemistry A, 119 (2015) 4891 4897. https://doi.org/10.1021/acs.jpca.5b02942

[5] A. Pabst, Structures of some tetragonal sheet silicates, Acta Crystallographica, 12 (1959) 733739. https://doi.org/10.1107/S0365110X5900216X

[6] F. Mazzi, A. Pabst, Reexamination of cuprorivaite, American Mineralogist: Journal of Earth and Planetary Materials, 47 (1962) 409-411.

[7] B. Errington, G. Lawson, S.W. Lewis, G.D. Smith, Micronised Egyptian blue pigment: a novel near-infrared luminescent fingerprint dusting powder, Dyes and Pigments, 132 (2016) 310-315. https://doi.org/10.1016/j.dyepig.2016.05.008

[8] M. Weller, Inorganic materials chemistry: OUP primer 23, Oxford Univerity Press, 1992.

[9] A. Lluveras, A. Torrents, P. GirÁLdez, M. Vendrell-Saz, Evidence for the use of Egyptian blue in an $11^{\text {th }}$ century mural altarprice by SEM-EDS, FTIR and SRXRD (church of Sant Pere, Terrassa, Spain), Archaeometry, 52 (2010) 308-319. https://doi.org/10.1111/j.1475$\underline{4754.2009 .00481 . x}$

[10] P. Mirti, L. Appolonia, A. Casoli, R.P. Ferrari, E. Laurenti, A. Amisano Canesi, G. Chiari, Spectrochemical and structural studies on a roman sample of Egyptian blue, Spectrochimica Acta Part A: Molecular and Biomolecular Spectroscopy, 51 (1995) 437-446. http://doi.org/10.1016/05848539(94)E0108-M

[11] H.M. Mahmoud, L. Papadopoulou, Archaeometric analysis of pigments from the tomb of Kakht-Djehuty (TT189), El-Qurna Necropolis, upper Egypt, ArcheoSciences, (2013) 19-33. https://doi.org/10.4000/archeosciences.3967

[12] S. Bruni, F. Cariati, F. Casadio, L. Toniolo, Spectrochemical characterization by micro-FTIR spectroscopy of blue pigments in different polychrome works of art, Vibrational Spectroscopy, 20 (1999) 15-25. https://doi.org/10.1016/S0924-2031(98)00096-4 